\title{
Study on Influencing Factors of Mobile Internet on Enterprises' Management Capability
}

\author{
Tao $\mathrm{Fu}$ \\ Panyapiwat Institute of Management \\ Bangkok, Thailand \\ weilove517@163.com
}

\author{
Ersi Liu* \\ Yunnan University of Finance and Economics \\ Kunming,China \\ Liuersi309@126.com
}

\begin{abstract}
This paper uses the methods of literature review, expert interview, and questionnaire survey to study the seven characteristics of mobile Internet which have impact on enterprises' management capability in comparison with desktop Internet, and further uses the Exploratory Factor Analysis (EFA) method to find out that space-time factor, convenience factor, and the ability of providing location-based services are the three major common factors. The findings lay a theoretical foundation for further studies on how to use mobile Internet to improve enterprises' management capability.
\end{abstract} EFA

Keywords—mobile Internet, enterprises' management capability

\section{INTRODUCTION}

With the implementation of Chinese government's "Belt and Road Initiative", the enterprises both in Yunnan, China and neighboring countries of South Asia and Southeast Asia have started a larger scale and higher level of international communication and cooperation. Strengthening of international cooperation has presented borderless information flow and management for enterprises, which sets stricter requirements for enterprises to use information technology for business management. In the traditional Internet era, however, due to the relatively backward of social and economic development in Yunnan and in neighboring regions of South Asia and Southeast Asia along the "Belt and Road", the enterprises did not have much utilization of information technology. However, with the release of Guiding Opinions on Accelerating the Construction of High-Speed Broadband Networks, Boosting Internet Speed and Lowering Internet Charges by the State Council of China in May 2015, the three major operators have launched a variety of measures to accelerate the development of mobile Internet, making wireless access become the mainstream way of accessing the Internet. The number of Chinese netizens accessing the Internet by $3 \mathrm{G} / 4 \mathrm{G}, \mathrm{WiFi}$, and other ways of mobile access has increased significantly. In 2016, the proportion of Chinese netizens browsing Internet with mobile phones reached 95.1\%. Meanwhile, countries in South Asia and Southeast Asia have also entered the high-speed development stage for network infrastructure construction with the development of mobile Internet. Both the application rate and penetration rate of wireless access have exceeded those of traditional desktop Internet. It has brought a new development opportunity for
Yunnan, China and the neighboring countries in South Asia and Southeast Asia to realize leapfrog development andnarrow the gap with developed regions by utilizing the technological advantages of mobile Internet to improve the management capability and efficiency of enterprises is necessary.

The key point of study on how to utilize the mobile Internet to improve enterprises' management capability and efficiency is to find out the similarities and differences between mobile Internet and desktop Internet in terms of their impact on enterprises' management capability and to find out the representative common assessment factors. It has been found from literature review that there is few study on this topic in the academic field. Therefore, this paper attempts to use the EFA method to find out the key factors of mobile Internet that have impact on enterprises' management capability through literature review, expert interview, and questionnaire survey, to lay a theoretical foundation for further studies on how to utilize mobile Internet to improve enterprises' management capability and efficiency.

\section{THEORY AND ANALYSIS OF MOBILE INTERNET CHARACTERISTICS}

\section{A. Relevant Theoretical Basis}

Mobile Internet emerges due to involvement of mobile communication network, and mobile Internet mainly consists of mobile communication network, portable terminals, Internet content, and the business models relying on mobile network innovation. Mobile Internet has broken through the time and space limitations of traditional information dissemination and changed the way of information transmission in the past. From the aspect of technology, mobile Internet is a new technology and has a breakthrough change compared with desktop Internet. But from the aspect of management, compared with desktop Internet and desktop Internet-based information management system, mobile Internet and mobile Internet-based information management system are of great inheritance and continuity. Based on the comparison between mobile Internet and desktop Internet, Zhong Wei (2013) has obtained the characteristics analysis diagram of mobile Internet (Figure I). This figure indicates that mobile Internet is a product generated by the mobilization of desktop Internet and the Internet transformation of mobile communication network. The study on how mobile Internet

\footnotetext{
*Corresponding author
} 
affects the enterprises' management capability can be started from the characteristics of mobile Internet, based on the studies on how desktop Internet-based and desktop Internet- based management information systems affect the enterprises' management capability.

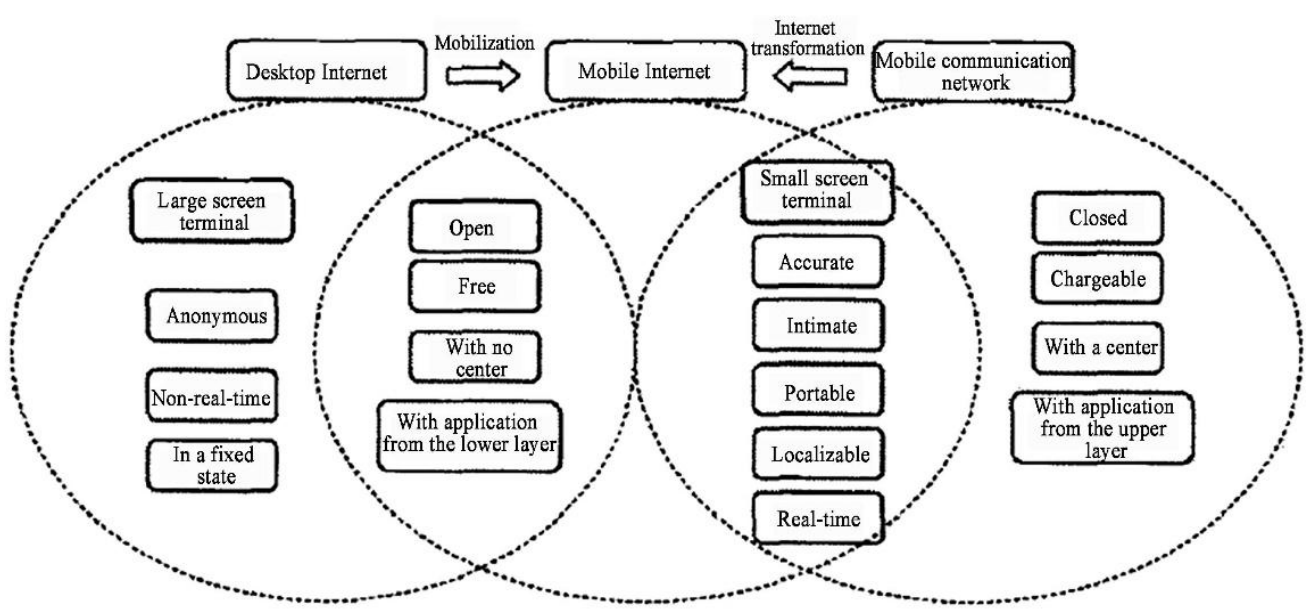

Figure. 1. Analysis of Characteristics of Mobile Internet (Source: Zhong Wei (2013))

\section{B. Analysis of Characteristics of Mobile Internet}

According to CNNIC's statistical report [7], the number of mobile Internet users in China is 620 million currently, and the number of users browsing Internet only with mobile phones is 127 million. It can be seen that the penetration rate of mobile Internet in China is very high. This popularity will have a corresponding impact on business management in the aspects of staff and customer relations. Therefore, popularity is considered as one of the characteristics of mobile Internet in this paper. It can also be concluded from the CNNIC's report that in 2015, 20-29-year-old users were major Internet users in China, accounting for $29.9 \%$. Although the proportion of over-40-year-old users increased in 2015 compared with that in 2014, young users still accounted for the largest proportion. Therefore, younger users are also considered as one of the characteristics in this paper.

For use of mobile Internet, compared with that of desktop Internet, the network access device is mobile phone, the basic personal communication tool. Internet access does not require PC or other access devices any more. Therefore, for individuals, compared with the traditional PC Internet, Internet access in a mobile way has the advantages of lower cost and lower entry threshold. For enterprises, the application of mobile Internet relies heavily on various cloud service platforms. Compared with the traditional information management system, the cloud computing-based Internet service platform has the advantages of lower cost and lower entry threshold for enterprises. Therefore, the characteristic of low cost and entry threshold is considered as one of the characteristics of mobile Internet in this paper. In addition, considering that the most network terminals are mobile phones and mobile numbers are subject to identity authentication currently almost in all countries, coupled with the locating ability of mobile Internet, the problem of involving personal privacy is also considered as one of the characteristics of mobile Internet in this paper.
In addition, many scholars at home and abroad have also summed up many characteristics of mobile Internet during their studies. Wu Jiyi et al. [5] pointed out that the basic characteristics of mobile Internet included terminal mobility, business timeliness, service convenience, and strong relevance of business/terminal/network. Wu Changqi [1] and Wei Lin [4] defined the convenience of mobile services as one of the characteristics of mobile Internet. Zhang Nanan [2] et al. also pointed out that mobile Internet could transmit the information obtained to the desired object in an effective and timely way and that mobile Internet had the characteristics of "being allday online", "easy and timely access to information", and "convenient information sharing." Wang Li [3], Wu Changqi [1], and Zhang Nanan [2] et al. defined the fragmentation of time and location of network access as one of the characteristics of mobile Internet.

Through literature review and summary, this paper draws out 12 characteristics of mobile Internet in comparison with desktop Internet: X1: terminal mobility; X2: all-day "online"; $\mathrm{X} 3$ : provision of location-based services; X4: fragmentation; X5: convenient and timely access to information; X6: low cost and entry threshold; X7: convenient use of business services; X8: convenient interaction; X9: convenient information sharing; X10: younger users; X11: popularity among users; $\mathrm{X} 12$ : involving personal privacy.

\section{QUESTIONNAIRE DESIGN AND SURVEY}

Through literature review and summary, this paper draws out 12 characteristics of mobile Internet in comparison with desktop Internet. For the purposes of verifying the results, finding out the nature and classification of mobile Internet characteristics, and determining whether these characteristics are the representative common assessment factors, a questionnaire survey was conducted. The survey objects include experts and scholars studying business management and information technology and executives of some small- and 
medium-sized enterprises. The questionnaire was designed into two parts: the first part is mainly about the background information of respondents, and the second part is designed for the respondents to provide information on the relevance of the proposed 12 mobile Internet characteristics to the enterprises' management capability. Likert Scale was adopted for the survey. The respondents were asked to describe whether the proposed characteristics would have an impact on enterprises' management capability based on their own studies and work experience.

During the questionnaire design, a small-sample pre-test was conducted. In the test, many experts doubted $\mathrm{X} 8$, convenient interaction and $\mathrm{X} 9$, convenient information sharing. According to them, the process of interaction was also the process of information transmission, so the two characteristics had no big difference, which might result in a homogeneity error. They recommended to combine the two characteristics into one, convenient information sharing. For X6, low cost and entry threshold, the experts thought that this characteristic had an impact on enterprises' management capability. But the information technology experts and enterprise executives suggested that the characteristic of low cost and entry threshold of mobile Internet was only valid for access equipment and Internet costs, while for business management, since it also involved cloud computing, research and

development of mobile Internet-based information management system, and other factors, and related systems have not been widely used currently, it was not appropriate to consider this characteristic as a typical one of mobile Internet. After accepting the recommendations of pre-test experts, we removed items X6 and X8 from the large-sample survey.

During the large-sample survey, 54 respondents were surveyed by the means of interview or telephone survey. From the aspect of research direction, these respondents include 17 scholars of information technology, accounting for 31.4\%, 26 scholars of business management, accounting for $48 \%$, and 11 enterprise executives, accounting for $20 \%$. Among the scholars (non-enterprise executives), 33 have senior titles or above, accounting for $61 \%$.

\section{STUDY RESULTS}

\section{A. Frequency Statistics}

SPSS 19.0 is used as the statistical analysis software for this survey. First, the frequency statistics method is used to verify whether the 10 mobile Internet characteristics will influence enterprises' management capability. table:

The frequency statistical data are listed in the following

TABLE I. THE FREQUENCY STATISTICAL DATA

\begin{tabular}{|c|c|c|c|c|c|c|c|c|c|c|}
\hline \multicolumn{11}{|c|}{ Statistics } \\
\hline & $x 1$ & $\times 2$ & $x 3$ & $\overline{X 4}$ & $\times 5$ & $\overline{X 6}$ & $x 7$ & $x 8$ & $\times 9$ & $\mathrm{X10}$ \\
\hline Valid & 54 & 54 & 54 & 54 & 54 & 54 & 54 & 54 & 54 & 54 \\
\hline Missing & 0 & 0 & 0 & 0 & 0 & 0 & 0 & 0 & 0 & 0 \\
\hline Mean value & 1.3148 & 1.4259 & 1.7963 & 1.2222 & 1.4630 & 1.3889 & 1.4074 & 3.3333 & 3.2222 & 3.7593 \\
\hline Mode & 1.00 & 1.00 & 1.00 & 1.00 & 1.00 & 1.00 & 1.00 & 3.00 & 3.00 & 5.00 \\
\hline Standard deviation & .46880 & .49913 & .80984 & .41964 & .50331 & .49208 & .49597 & .91115 & 1.02178 & 1.18058 \\
\hline Minimum value & 1.00 & 1.00 & 1.00 & 1.00 & 1.00 & 1.00 & 1.00 & 1.00 & 1.00 & 1.00 \\
\hline Maximum value & 2.00 & 2.00 & 3.00 & 2.00 & 2.00 & 2.00 & 2.00 & 5.00 & 5.00 & 5.00 \\
\hline
\end{tabular}

The questionnaire survey indicates that, the mean values of the three characteristics, including X8 (younger users), X9 (popularity among users), and X10 (involving personal privacy), all exceed 3 with a standard deviation around 1 . During the follow-up with interviewees, most of them believe that, although these characteristics are acquired by mobile Internet when compared with traditional desktop Internet, the three characteristics may have limited impact on enterprise management or enterprises' management capability. Instead, they may be significant for analysis upon user groups and enterprise business modes. Therefore, the three characteristics can be deleted since they are negligible for studying the mobile Internet's impact on enterprises' management capability.

\section{B. Analysis of Exploratory Factors}

Through the frequency statistics analysis, this paper has defined 7 characteristics of mobile Internet that influence enterprises' management capability, and further discusses whether related characteristics have representative common assessment factors with the exploratory factor analysis (EFA) method.

SPSS statistical data prove that the sample is suitable for EFA. Among them, the variance value of common factors extracted from 7 principal components is between 0.524 and 0.938 , the KMO value is 0.606 , the chi-square value of Bartlett's Test of Sphericity is 85.51, and $\mathrm{P}<0.000$. This paper uses the principal component analysis and varimax rotation method, and extracts 3 factors after orthogonal rotation. The total variance of cumulative explanatory variables is 71.201 , and the rotational component matrix's explanatory degrees upon the 7 variables are listed in the following table: 
TABLE II. ThE Rotational COMPONENT MATRIX'S EXPLANATORY DEGREES UPON THE 7 VARIABLES

\begin{tabular}{|l|l|l|l|l|}
\hline \multicolumn{2}{|l|}{ Variable } & \multicolumn{3}{|c|}{ Principal Component } \\
\cline { 3 - 5 } & & 1 & 2 & 3 \\
\hline X1 & Terminal mobility & 0.915 & & \\
\hline X2 & All-day "online" & 0.844 & & \\
\hline X3 & Provide location-based service & & 0.129 & 0.948 \\
\hline X4 & Surf Internet at fragmented time & 0.772 & 0.102 & \\
\hline X5 & $\begin{array}{l}\text { Convenient and timely access to } \\
\text { information }\end{array}$ & & 0.745 & 0.118 \\
\hline X6 & Convenient information sharing & & 0.693 & 0.199 \\
\hline X7 & Convenient use of business services & & 0.825 & \\
\hline
\end{tabular}

From the above table, we can see principal component 1 explains three mobile Internet characteristics, namely the terminal mobility, all-day "online", and surfing Internet at fragmented time, which just reflect characteristics of the mobile Internet and desktop Internet that they are not bound to time and space factors. This paper summarizes these characteristics as space-time factors of mobile Internet.

Principal component 2 explains the convenience characteristics, including the convenient and timely access to information, convenient information sharing, and convenient use of business services, which just reflect the convenience of mobile Internet on information access, transfer, and use compared with the traditional desktop Internet. This paper summarizes them as convenience factors of mobile Internet.

Furthermore, principal component 3's explanatory degree upon providing location-based service reaches 0.948 , while principal component 1 's and principal component 2's explanatory degree upon it is negative or very low. Theoretically, mobile Internet can provide location-based service. This neither has direct connection with convenient information use of mobile Internet, nor has theoretical common points with time-space factors used. Therefore, This paper takes the mobile Internet's provision of location-based service as a single principal component.

\section{CONCLUSIONS}

This paper compared differences between mobile Internet and desktop Internet, figured out seven characteristics of mobile Internet that influence enterprises' management capability based on literature review and questionnaire survey, and further explored representative common assessment factors with the EFA method. The factors are space-time factors of use, convenience factor, and provision of locationbased service respectively. Compared with previous researches on mobile Internet from the enterprise management perspective, this paper identified key factors and measurement indicators of mobile Internet that may have impact on enterprises' management capability, and laid the foundation for conducting in-depth study on the way that mobile Internet affects enterprises' management capability and the transmission mechanism that mobile Internet improves enterprises' management capability.

\section{ACKNOWLEDGMENT}

I want to say thanks to Professor Liu Ersi, my doctoral dissertation advisor for his specialized guidance, and to Professor Yi Hong and other experts, to Yunnan Management and Public Service Information Engineering Technological Research Center, and Yunnan Middle and Small-Sized Enterprises Development Research Institute, who have helped me in expert interview and questionnaire survey when I wrote this paper.

\section{REFERENCES}

[1] C.Q. Wu, "Analysis upon Current Structure and Development Trend of Chinese Mobile Internet Market," Industrial Economy, pp. 1-3, May 2015

[2] N.N. Zhang, "Studies on Mobile Internet Technologies and their applications in Campus Interactive Learning Platforms Teaching and Education Informatization," vol. 17, 2015, pp. 184-185.

[3] L. Wang, "Mobile Internet Ideas, Beijing Tsinghua University Press," 2015.

[4] L.Wei, "Mobile Internet-based WeChat E-Commerce Development Research," Price Monthly, 2014, pp. 59-61.

[5] J.Y. Wu, "Generals about Mobile Internet Research," SCIENCE CHINA Information Sciences, vol. 45, 2015, pp. 45-69.

[6] G.F. Zhao, "Business Access Feature of Mobile Internet," Chinese Journal of Computers, vol. 36, 2013, pp. 1388-1398.

[7] CNNIC,39th Chinese Internet Development Statistics Report, 2017 